\title{
Preparation of Photoactive Tungsten-doped Anatase Nanotubes Using Hydrothermal Technique
}

\author{
H.A. El Nazer and A.M. EL-Rafei ${ }^{*}$ \\ Photochemistry Dept. and *Refractories, Ceramics \& Building \\ Materials Dept., National Research Centre, Dokki, Cairo, \\ Egypt. P.O. 12622.
}

\begin{abstract}
T ITAnIA $\left(\mathrm{TiO}_{2}\right)$ and tungsten doped titania $\left(\mathrm{W}-\mathrm{TiO}_{2}\right)$ nanoshpheres were prepared by the sol-gel method, while tungsten doped titania nanotubes was formed by the hydrothermal process. The structure and the morphology of the prepared photocatalysts have been characterized using X-ray diffraction (XRD) and high resolution transmission electron microscope (HRTEM) techniques, respectively. XRD results of the $\mathrm{W}-\mathrm{TiO}_{2}$ powder, prepared by the sol - gel method and the hydrothermal method showed that anatase structure was formed. HRTEM images illustrate that the average diameter of the as-synthesized $\mathrm{W}-\mathrm{TiO}_{2}$ nanosphers was about $70 \mathrm{~nm}$ and the nanotubes, $\mathrm{W}-\mathrm{TiO}_{2} \mathrm{NT}$, have an outer diameter ranging from 8 to $10 \mathrm{~nm}$ and inner diameter of 2 to $3 \mathrm{~nm}$ and a length of few hundreds of nanometers. The photocatalytic performance of the prepared photocatalysts was studied through the degradation of acid orange dye (AO7). Higher efficiency for degradation of AO7 was obtained using $\mathrm{W}-\mathrm{TiO}_{2} \mathrm{NT}$ compared with $\mathrm{TiO}_{2}$ and $\mathrm{W}-\mathrm{TiO}_{2}$ nano-powders. The results show that the dye removal was $99.88,95.00$ and $81.00 \%$ within 60 minutes in the case of using W$\mathrm{TiO}_{2} \mathrm{NT}$ and $\mathrm{W}-\mathrm{TiO}_{2}$ nanospheres and $\mathrm{TiO}_{2}$ nanospheres, respectively and the absorption edge shifts toward visible light region for both $\mathrm{W}-\mathrm{TiO}_{2}$ nano-powders and NT.
\end{abstract}

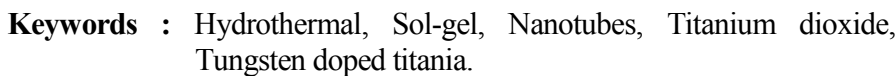

Photocatalytic degradation of some organics has been studied using some metal oxide or sulfide photocatalysts. The most commonly studied photocatalysts include: $\mathrm{TiO}_{2}$, $\mathrm{ZnO}, \mathrm{WO}_{3}, \mathrm{Fe}_{2} \mathrm{O}_{3}$, and $\mathrm{ZnS}^{(1)}$.

The oxidation ability is an important factor for degradation of organics using photocatalytic oxidation technique. The photo generation of valence band holes $\left(\mathrm{h}_{\mathrm{vb}}\right)$ and creation of hydroxyl radicals ( $\mathrm{HO} \cdot \mathrm{ads}$ ) are the key factors for using the photocatalyst in the degradation of organic compounds. This is also true if the excited conduction band electrons $\left(\mathrm{e}^{-} \mathrm{cb}\right)$ have reducing power that is sufficient for the reduction of oxygen molecules to superoxide ${ }^{(2)}$.

The electron-hole pairs formation is considered to be an important key factor in the photocatalytic oxidation processes of organics for $\mathrm{H}_{2} \mathrm{O}$ and $\mathrm{CO}_{2}$. The energy of the semiconductor's band gap may define the irradiation energy that may be required

\#Corresponding author emails: am.amin@nrc.sci.eg and amira_elrafei@yahoo.com 
for excitation an electron from the valence band to the conduction band, resulting in leaving a positively charged hole in the valence band, $\mathrm{h}_{\mathrm{vb}}^{+}$. If the needed excitation energy of a given semiconductor to form charge carriers is outside the wavelength range of the incident irradiation energy, the photocatalyst is useless for the degradative oxidation of organic compounds without electronic modification ${ }^{(3-5)}$.

Titanium dioxide $\left(\mathrm{TiO}_{2}\right)$ photocatalyst has good oxidation ability as well as band gap energy that could absorb UV radiation. The ultraviolet radiation is considered to make up only about $5 \%$ of the solar energy. The doping of titanium dioxide with metals, non-metals and other metal oxides is of great interest for the improvement of visible light absorption and/or the decrement of recombination rate of excited electrons and holes. The reductive deposition of some noble metals (e.g. Pt or $\mathrm{Au}$ ) onto the titanium dioxide surface is considered to be one of the most promising doping techniques. The splitting of water into $\mathrm{H}_{2}$ and $\mathrm{O}_{2}$ could not be carried out by photocatalysis techniques using undoped $\mathrm{TiO}_{2}$. When nanoparticles of platinum are deposited on the surface of titanium dioxide, an increment in the $\mathrm{H}_{2}$ production rate from adsorbed water molecules may be observed ${ }^{(6)}$. This may be attributed to the transfer of electrons from the $\mathrm{TiO}_{2}$ surface to the metal resulting in the reduction of water molecules to hydrogen. The high prices of noble metals make them difficult to be used for industrial scale. Some transition metals, i.e. Fe and $\mathrm{Cr}$, have been used as dopants ; in conclusion, these metals are considered to act as electron and hole traps as well as decrease the recombination rate of electron hole pairs ${ }^{(7-10)}$.

Doping with tungstate has shown a shift of the band gap of $\mathrm{TiO}_{2}$ to be closer to the visible spectrum (2.86 eV vs. $3.21 \mathrm{eV}$ for pure anatase). This result is highly promising since increment the solar energy absorption is considered to be one of the important goals of titanium dioxide scientific research. The enhancement of photocatalytic degradation rate is also mentioned for many of these photocatalysts compared to pure anatase and Degussa. This improvement in the phtotcatalytic reaction may be attributed to an increment of surface acidity of the photocatalyst surface as well as the trapping of charge carriers ${ }^{(11,12)}$. Azodyes are chemical dyes that are hazardous to environment ${ }^{(13)}$. The discharge of large amounts of these dyes into the environment via the dye effluents from textile mills causes problems for municipal wastewater treatment facilities.

The present work concerns with the preparation of $\mathrm{TiO}_{2}$ nanosphere, $\mathrm{W}-\mathrm{TiO}_{2}$ nanosphere and $\mathrm{W}-\mathrm{TiO}_{2}$ nanotube photocatalysts. The oxidative efficiency of the prepared photocatalysts has been evaluated by the degradation of azodye such as Acid Orange 7 (AO7).

\section{Experimental Procedures}

Preparation of anatase \& tungsten-doped anatase nanoparticles

A $\mathrm{TiO}_{2}$ transparent sol was prepared by mixing of $17.5 \mathrm{~g}$ titanium(IV) butoxide $\mathrm{Ti}(\mathrm{O}-\mathrm{nBu})_{4}$ reagent grade (Sigma-Aldrich), $120 \mathrm{ml}$ ethanol, $15 \mathrm{ml}$ acetic acid, and 5 $\mathrm{ml}$ deionized water. The mixture was aged for $24 \mathrm{hr}$ and was stirred at ambient Egypt. J. Chem. 59, No.6 (2016) 
temperature. In case of preparation of tungsten doped titania, $60 \mathrm{ml}$ of aqueous solution containing $4.56 \mathrm{~g}$ ammonium paratungestate (Sigma-Aldrich, $\geq 99 \%$ ) $\left(\left(\mathrm{NH}_{4}\right)_{10} \mathrm{~W}_{12} \mathrm{O}_{41}, \mathrm{~F} . \mathrm{W} .=3042.55\right)$ was added under vigorous stirring to titania sol dropwise over $2 \mathrm{hr}$ until the $\mathrm{W}-\mathrm{TiO}_{2}$ gel is formed. The $\mathrm{TiO}_{2}$ gel was aged two days. The $\mathrm{W}-\mathrm{TiO}_{2}$ gel was then dried with a rotary evaporator at $150{ }^{\circ} \mathrm{C}$. After drying, the samples were collected and ground using a mill. The $\mathrm{TiO}_{2}$ powder was calcinated at $450{ }^{\circ} \mathrm{C}$ for three hours ${ }^{(14)}$.

\section{Preparation of $\mathrm{W}-\mathrm{TiO}_{2}$ nanotubes}

$\mathrm{W}-\mathrm{TiO}_{2}$ nanotubes were synthesized by the hydrothermal method. A conversion from nanoparticles to nanotubes was achieved by treating the $\mathrm{W}-\mathrm{TiO}_{2}$ nanoparticle with $10 \mathrm{M} \mathrm{NaOH}$ (ADWIC, 96\%) at $150{ }^{\circ} \mathrm{C}$ for $24 \mathrm{hr}$ in a Teflon-lined autoclave. The precipitates were neutralized thoroughly with $\mathrm{HCl}$, then washed with deionized water, filtered and dried at $100^{\circ} \mathrm{C}$. The detailed procedure is reported elsewhere ${ }^{(15,16)}$

\section{Characterization}

X-ray diffraction (XRD) analysis of the prepared powders was performed using BRUKUR D8 ADVANCE with secondary monochromatic beam CuK $\alpha$ radiation at $40 \mathrm{Kv}$ and $40 \mathrm{~mA}$, whereas the microstructure of the prepared powders was examined using high resolution transmission electron microscope (HRTEM), JEOL, JEM-2 100 working voltage at $200 \mathrm{kV}$. The morphology of $\mathrm{TiO}_{2}$ doped with tungsten was examined using Field emission scanning electron microscopy (FESEM) using JOEL Model JED-2300 instrument. The tungsten was observed by Energy-dispersive X-ray spectroscopy (EDX). The EDX spectra of the $\mathrm{TiO}_{2}$ doped with tungsten was recorded on a JOEL Model JED-2300 instrument.

\section{Photocatalytic experiments}

The experiments were carried out using a photoreactor with fifteen fluorescent bulbs generating approximately $120 \mathrm{~W} \mathrm{~m}^{-2}$ from $365-600 \mathrm{~nm}$. Prior to irradiation, all of the samples were sonicated for $10 \mathrm{~min}$ to break up the photocatalyst agglomerates powder. During the photoreaction, the samples were stirred and the temperature held constant at $25-30{ }^{\circ} \mathrm{C}$. For all runs, the amount of photocatalyst suspended in the dye solution was kept constant at $100 \mathrm{mg} / \mathrm{l}$. the initial dye concentration was $250 \mathrm{mg} / \mathrm{l}$. The photocatalyst dose among the various runs was kept constant. A magnetic stirrer guaranteed satisfactory powder suspension and the uniformity of the reacting mixture. Oxygen was bubbled during this stage in order to ensure the availability of the oxidant gas in the solution. The irradiation time was taken at the moment when the lamp was switched on. Samples for analyses were withdrawn at fixed intervals of time. The dye concentration was analyzed using UV-visible spectrophotometer (Agilent-Carry 100). The maximum absorption wavelength for the acid orange 7 dye $\left(\lambda_{\max }\right)$ is $480 \mathrm{~nm}$. The removal dye efficiency was estimated by applying the following Equation (1):

Removal Dye Efficiency $(\%)=\left(\mathrm{C}_{0}-\mathrm{C} / \mathrm{C}_{0}\right) \times 100$ where $C_{\mathrm{o}}$ is the original dye content and $C$ is the residual dye in solution. 
The chemical oxygen demand (COD) was determined by an open-reflux dichromate titrimetric procedure, as described in standard methods ${ }^{(17)}$.

\section{Results and Discussions}

Phase composition of the as-synthesized samples and hydrothermally treated samples

Figure 1 shows XRD patterns of the as-synthesized $\mathrm{W}-\mathrm{TiO}_{2}$ powder, prepared by the sol - gel method and hydrothermal method. As indicated in these patterns, both two samples exhibit anatase structure according to JCPDS 21-1272; i.e. 25.33(101), 37.88(004), 47.98(200), 54.74(105), 62.80(204), 70.00(116), $75.16(301)$.

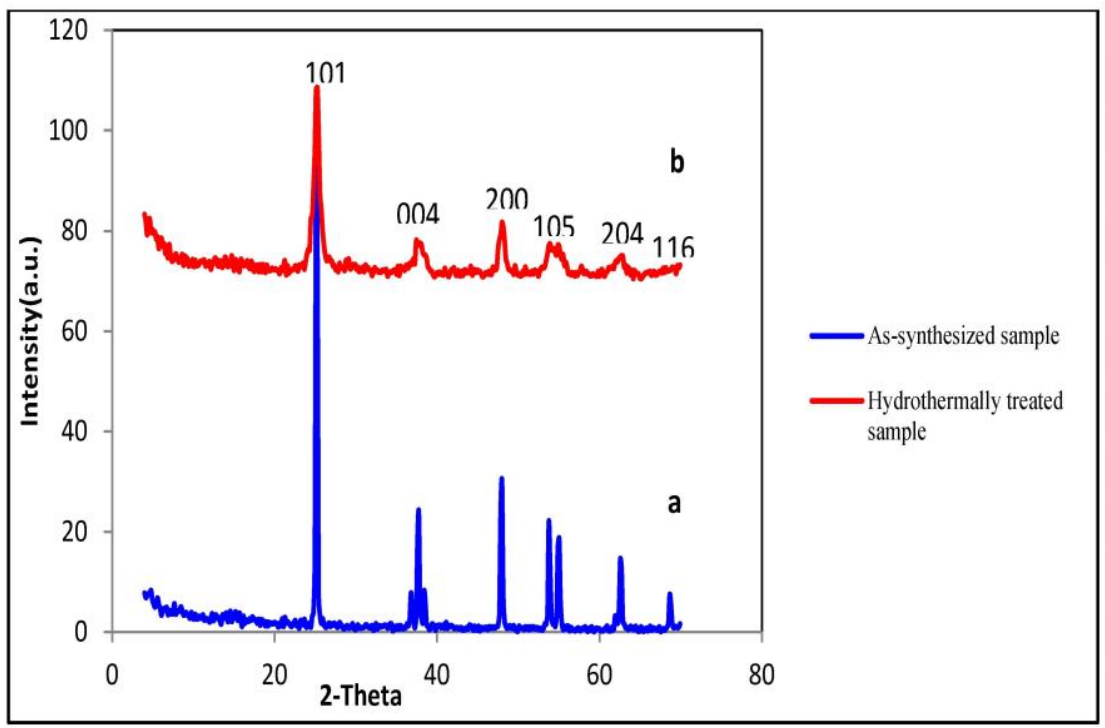

Fig. 1. XRD patterns of the as-synthesized $\mathrm{W}$-doped $\mathrm{TiO}_{2}$ powders: a) sol-gel sample b) Hydrothermally treated for $24 \mathrm{hr}$ at $150{ }^{\circ} \mathrm{C}$.

Morphology of as-synthesized $\mathrm{W}-\mathrm{TiO}_{2}$ and $\mathrm{W}$ - $\mathrm{TiO}_{2} \mathrm{NT}$

Figure 2 ( $a, b$ and c) shows HRTEM images of as-synthesized $\mathrm{W}-\mathrm{TiO}_{2}$ nanoparticles and the obtained $\mathrm{W}-\mathrm{TiO}_{2} \mathrm{NT}$ after the hydrothermal treatment with low and high-magnification, respectively. As-synthesized $\mathrm{W}-\mathrm{TiO}_{2}$ is nano-particle of pure anatase with an average diameter of about $70 \mathrm{~nm}$ as shown in Fig. 2(a).

The as-grown $\mathrm{W}-\mathrm{TiO}_{2}$ NTs are generally homogeneous, (Fig.2b), fine hollow open-ended tubes with a uniform diameter along their lengths. The nanotubes have an outer diameter ranging from 8 to $10 \mathrm{~nm}$ and inner diameter of 2 to $3 \mathrm{~nm}$ and a length of few hundreds of nanometers, showing narrow size distribution, as shown in Fig.2(c). It is clear from these figures a well identified multi walled nanotubular structure can be formatted as it is clear from these figures.

Egypt. J. Chem. 59, No.6 (2016) 


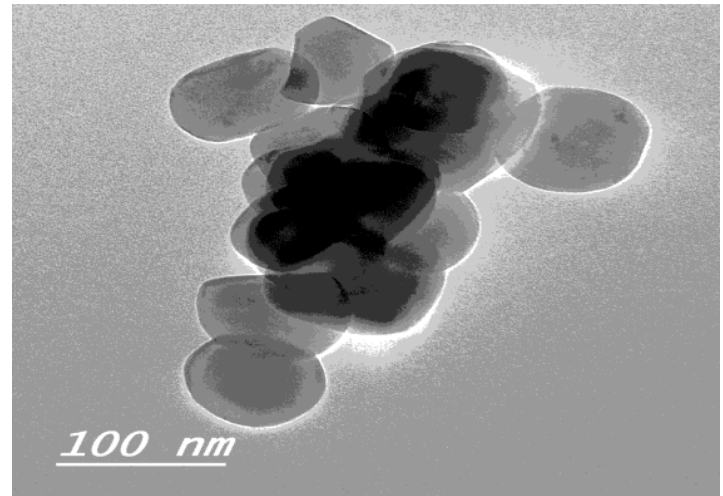

(a)

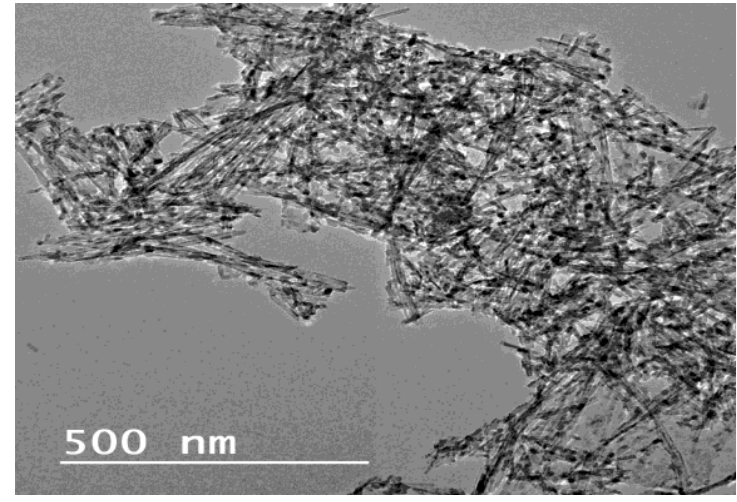

(b)

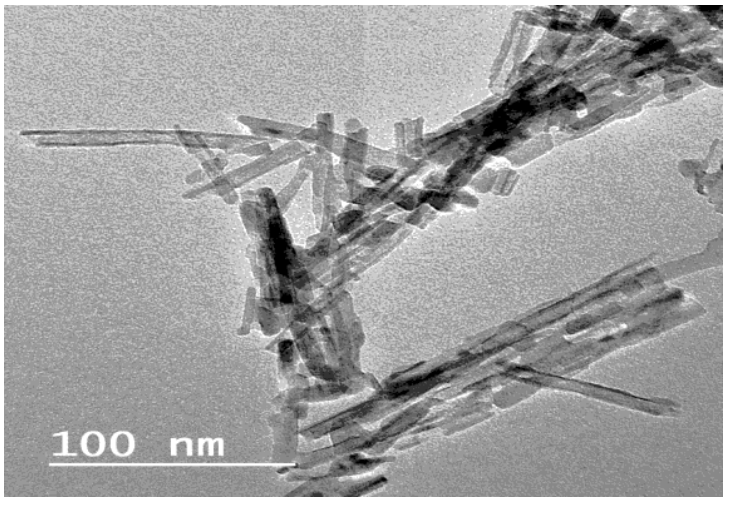

(c)

Fig.2. Typical HR-TEM images of as-prepared a) W-doped $\mathrm{TiO}_{2}$ and b) Wdoped TNTs c) high-magnification W-doped TNTs. 
One of the proposed mechanisms of the nanotube formation via the hydrothermal reaction is the formation of titanate containing alkali metal, first, during the hydrothermal treatment process using sodium hydroxide. Second, the ion exchange process of the alkali metal element has been occurred. The protonated titanate is then formed as a nano-sheet. Finally, the nanosheet converts to be a tubular structure by scrolling process for lowering the surface energy ${ }^{(18)}$.

\section{SEM/EDAX analysis of the $\mathrm{W}-\mathrm{TiO}_{2} \mathrm{NTS}$}

The SEM image revealed that the $\mathrm{W}-\mathrm{TiO}_{2}$ NT has smooth surfaces and uniformities in diameter size (Fig. 3a). Furthermore, the electron dispersive spectrum of the $\mathrm{W}-\mathrm{TiO}_{2} \mathrm{NT}$ is made. From this EDX spectrum, (Fig. 3b), a very weak signal for $\mathrm{W}$ and a very strong signal for Ti can be observed. The quantitative analysis of the $\mathrm{W}-\mathrm{TiO}_{2} \mathrm{NT}$ based on this spectrum showed that about $2.5 \%$ of $\mathrm{W}$ was present. This is consistent with the nominal amount of doped tungsten.

(a)

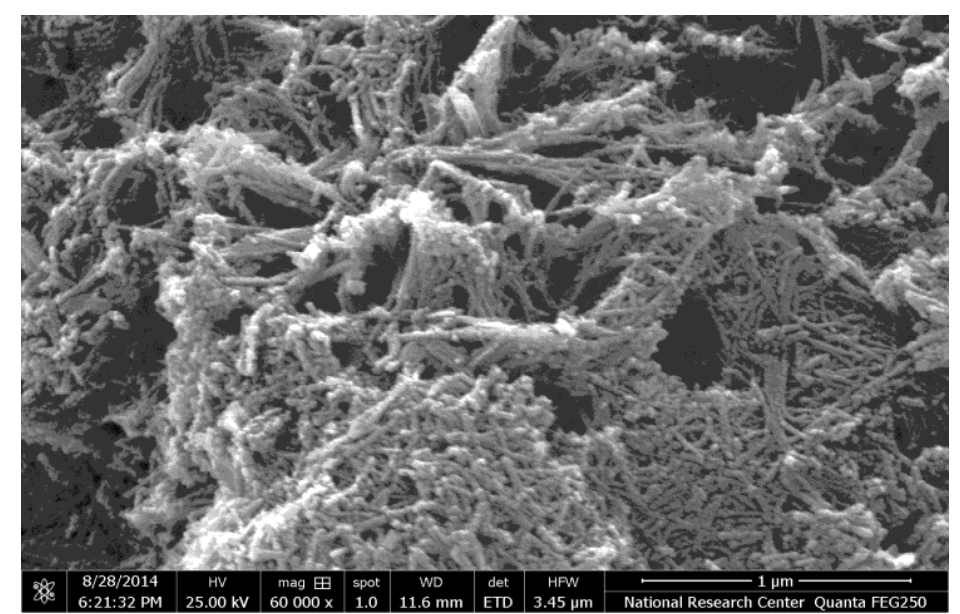

(b)

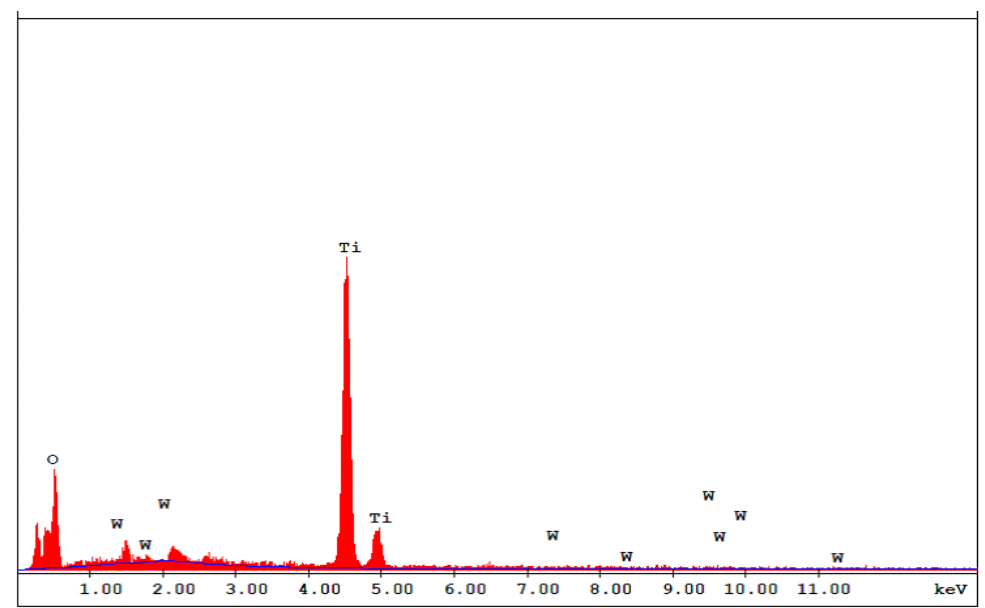

Fig. 3. (a) SEM image for W-doped W-TiO2 NT, (b) EDS spectra for W-doped W-TiO2 NT.

Egypt. J. Chem. 59, No.6 (2016) 
Photocatalytic performance

The photocatalytic degradation of AO7 was studied using the prepared photocatalysts. The structure of AO7 is shown in Fig. 4. The photolysis of AO7 dye was carried out in the absence of photocatalyst. The results showed that no significant dye or COD removal within 60 min of irradiation, (Fig. 5).<smiles></smiles>

Fig. 4. Structure of Acid Orange (AO7) dye .

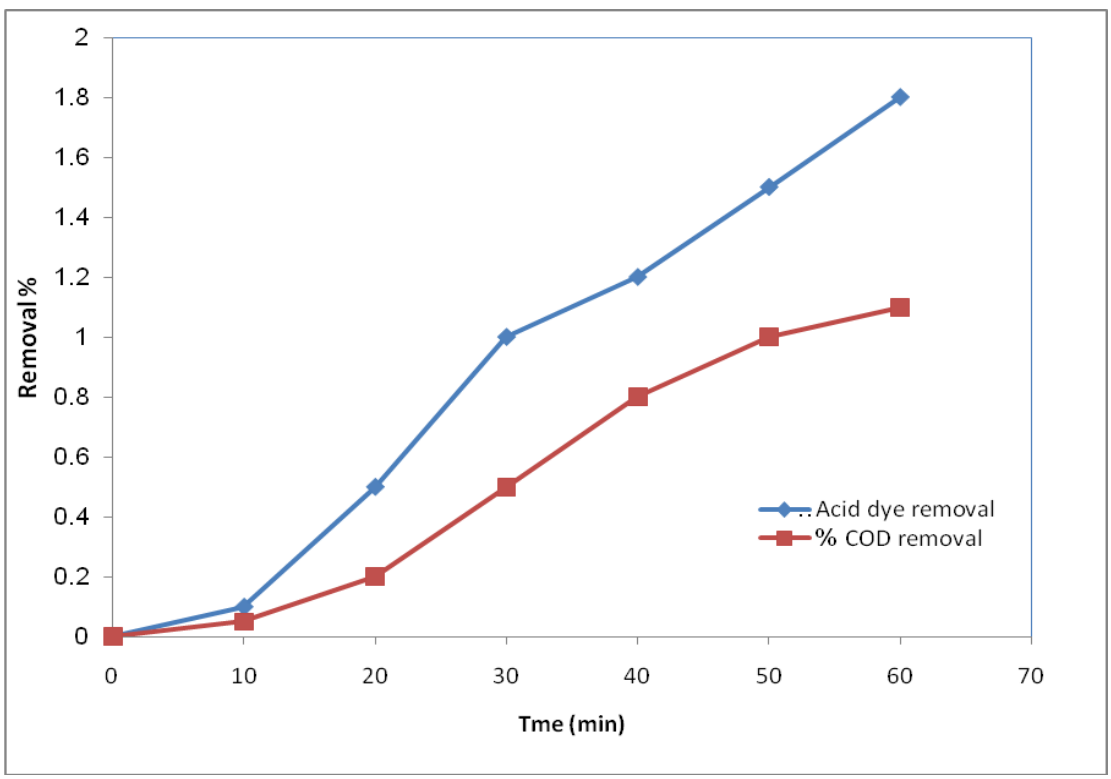

Fig. 5. Relationship between time of photolysis and the percentage of total dye and COD removal of acid orange dye in absence of Photocatalyst: $\mathrm{pH}=5$, and Temp $=25^{\circ} \mathrm{C}$.

The photocatalytic oxidation of $\mathrm{AO} 7$ experiment shows that the dye removal results were $99.88,95.00$ and $81.00 \%$ in the case of using $\mathrm{W}-\mathrm{TiO}_{2} \mathrm{NT}, \mathrm{W}-\mathrm{TiO}_{2}$ nanospheres and $\mathrm{TiO}_{2}$ nanospheres, respectively (Fig. 6). While the results of COD removal were 
$96.00,90.00$ and $62.00 \%$ in the case of using $\mathrm{W}-\mathrm{TiO}_{2} \mathrm{NT}, \mathrm{W}-\mathrm{TiO}_{2}$ nanospheres and $\mathrm{TiO}_{2}$ nanospheres, respectively, as shown in Fig. 7.

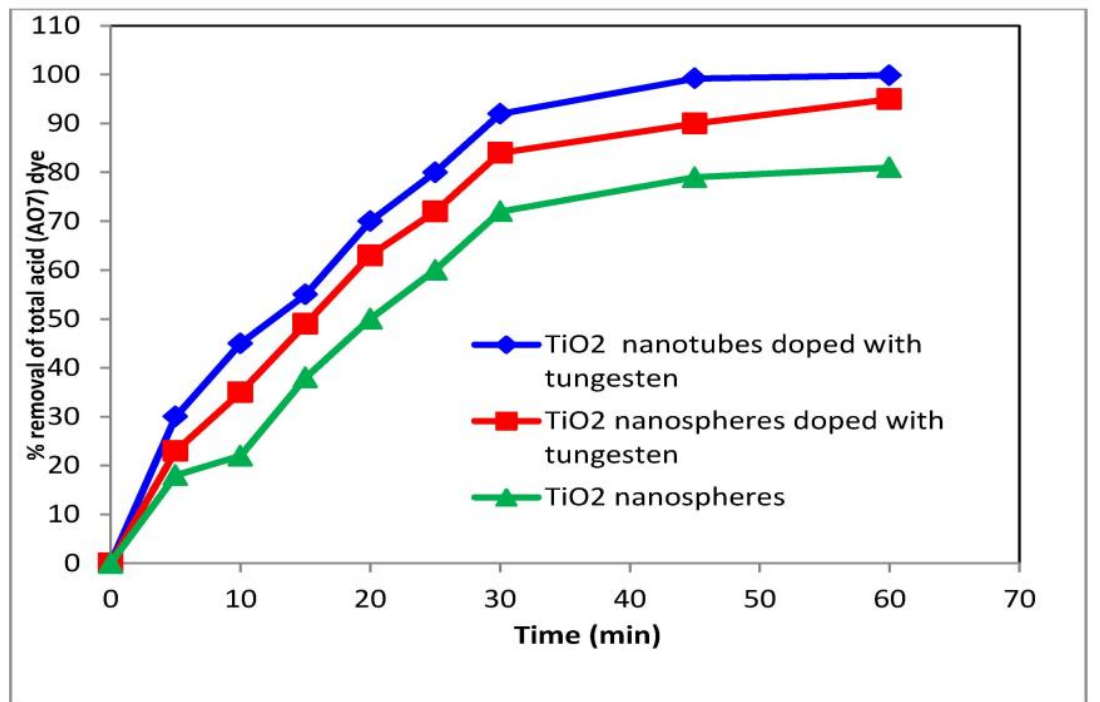

Fig. 6. Relationship between time of irradiation and the percentage of total Acid Orange dye removal using different photocatalysts. Photocatalyst: $100 \mathrm{mgl}^{-1}, \mathrm{pH}=5$ and Temp $=25^{\circ} \mathrm{C}$.

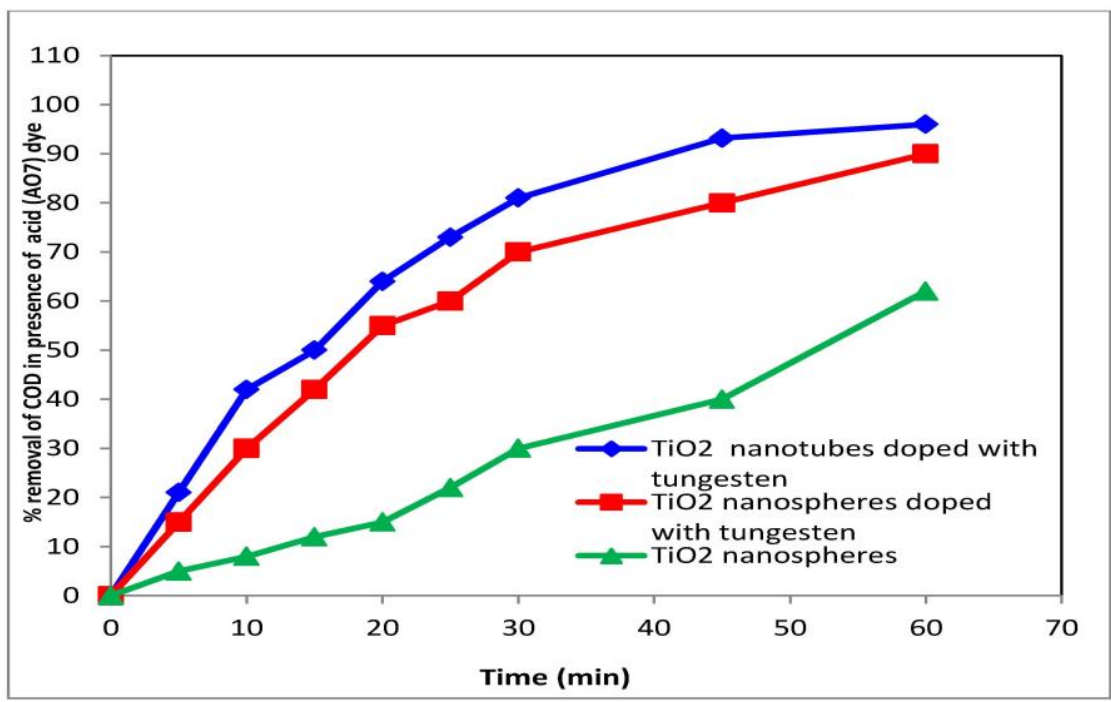

Fig. 7. Relationship between time of irradiation and the percentage of total COD removal in presence of acid orange dye using different photocatalysts. Photocatalyst: $100 \mathrm{mgl}^{-1}$, $\mathrm{pH}=5$, and $\mathrm{Temp}=25^{\circ} \mathrm{C}$.

Egypt. J. Chem. 59, No.6 (2016) 
$\mathrm{TiO}_{2}$ only exhibit the fundamental absorption band in the UV light region, while the absorption edge shifts towards the visible light region obviously for the $\mathrm{W}-\mathrm{TiO}_{2}$ and $\mathrm{W}-\mathrm{TiO}_{2} \mathrm{NT}$. The same behavior was observed with doping with earth ion ${ }^{(19)}$. The results indicate that the photocatalytic efficiency is relatively high in case of using nanotube morphology of $\mathrm{TiO}_{2}$ due to increment in the photocatalyst surface area ${ }^{(20)}$. This increment of photocatalytic efficiency was attributed to that when $\mathrm{W}$ ions in contact with the $\mathrm{TiO}_{2}$ surface; it could trap excited electrons in the $\mathrm{W}_{-} \mathrm{TiO}_{2}$ photocatalyst. During irradiation of $\mathrm{W}$ $\mathrm{TiO}_{2}$ photocatalyst, the excited electron may transfer from $\mathrm{O}^{2-}$ to $\mathrm{W}^{6+}$ and the $\mathrm{W}^{6+}$ reduces to $\mathrm{W}^{5+}$ as the electron trapping process is occurring. The oxidation of $\mathrm{W}^{5+}$ to $\mathrm{W}^{6+}$ may be performed by the oxygen present in the reaction mixture that could again trap the electrons resulting in increment of the photocatalytic activity ${ }^{(21)}$. Doping of $\mathrm{TiO}_{2}$ with tungsten may form junction that contributes in the separation of the photogenerated electron-hole pairs. This may enhance the photocatalytic activity of the doped photocatalyst ${ }^{(22,23)}$. The crystallinity of nanotubes may decrease the electron-hole recombination probability in bulk as well as increase the diffusion efficiency of electrons and holes to adsorbed reactants on the $\mathrm{TiO}_{2}$ surface to participate in the photocatalytic degradation reaction ${ }^{(24)}$.

\section{Conclusions}

Titania $\left(\mathrm{TiO}_{2}\right)$ and tungsten doped titania $\left(\mathrm{W}-\mathrm{TiO}_{2}\right)$ nanoparticles were prepared using sol-gel technique. Then transformation of tungsten doped titania nanoparticles into nanotubes $\left(\mathrm{W}-\mathrm{TiO}_{2} \mathrm{NT}\right)$ was achieved using hydrothermal technique. Comparison of the photocatalytic activity of the three photocatalyst was made. The results of the photocatalytic oxidation of $\mathrm{AO} 7$ showed that the dye removal was $99.88,95.00$ and $81.00 \%$ in the case of using $\mathrm{W}-\mathrm{TiO}_{2} \mathrm{NT}$, W$\mathrm{TiO}_{2}$ nanospheres and $\mathrm{TiO}_{2}$ nanospheres, respectively and the absorption edge shifts towards visible light region obviously for the $\mathrm{W}-\mathrm{TiO}_{2}$ and $\mathrm{W}-\mathrm{TiO}_{2} \mathrm{NT}$. COD removal was $96.00,90.00$ and $62.00 \%$ in the case of using $\mathrm{W}-\mathrm{TiO}_{2} \mathrm{NT}, \mathrm{W}-$ $\mathrm{TiO}_{2}$ nanospheres and $\mathrm{TiO}_{2}$ nanospheres, respectively.

\section{References}

1. Fox, M.A., Heterogeneous photocatalysis, Chem. Rev. 93, 341-357 (1993).

2. Halmann, M.M., "Photodegradation of Water Pollutants"; CRC Press: New York (1996).

3. Linsebigler, A.L., Lu, G. and Yates Jr., J.T., Photocatalysis on $\mathrm{TiO}_{2}$ surfaces: principles, mechanisms, and selected results. Chem. Rev. 95, 735758 (1995).

4. Jia, H. and He, W. et al., Generation of reactive oxygen species, electrons/holes, and photocatalytic degradation of rhodamine B by 
photoexcitedCdS and $\mathrm{Ag}_{2} \mathrm{~S}$ micro-nano structures. The Journal of Physical Chemistry, C 118 (37), 21447-21456 (2014).

5. Oppenländer, T., "Photochemical Purification of Water and Air"; WileyVCH: London (2003).

6. Emilio, C.A., Litter, M.I., Kunst, M., Bouchard, M. and ColbeauuJustin, C., Phenol photodegradation on platinized- $\mathrm{TiO}_{2}$ photocatalysts related to charge-carrier dynamics. Langmuir, 22, 3606-3613 (2006).

7. Thompson, T.L. and Yates, J.T., Surface science studies of the photo activation of $\mathrm{TiO}_{2}$-New photochemical processes. Chem. Rev. 106, 44284453 (2006).

8. Isley, S.L. and Penn, R.L., Relative brookite and anatase content in sol-gelsynthesized titanium dioxide nanoparticles, J. Phys. Chem. B 110, 1513415139 (2006).

9. Zhang, Z. and Maggard, P.A., Investigation of photocatalytically-active hydrated forms of amorphous titania, $\mathrm{TiO}_{2} \cdot \mathrm{nH}_{2} \mathrm{O}$, J. Photochem. Photobiol. A186, 8-13 (2007).

10. Do, Y.R., Lee, W., Dwight, K. and Wold, A., The Effect of $\mathrm{WO}_{3}$ on the photocatalytic activity of $\mathrm{TiO}_{2}$. J. Solid State Chem. 108, 198-201 (1994).

11. Wu, Q., Li, D., Chen, Z. and Fu, X., New synthesis of a porous $\mathrm{Si}^{-\mathrm{TiO}_{2}}$ photocatalyst: testing its efficiency and stability under visible light irradiation, J. Photochem. Photobiol. Sci. 5, 653-655 (2006).

12. Engweiler, J., Harf, J. and Balker, A., $\mathrm{WO} x / \mathrm{TiO}_{2}$ catalysts prepared by grafting of tungsten alkoxides: morphological properties and catalytic behavior in the selective reduction of $\mathrm{NO}$ by $\mathrm{NH}_{3}$. J. Catal. 159, 259-269 (1995).

13. Jaimes-Ramírez, R., Vergara-Sánchez, J. and Silva-Martínez, S., Solar assisted degradation of acid orange 7 textile dye in aqueous solutions by $\mathrm{Ce}-$ doped $\mathrm{TiO}_{2}$. Mexican Journal of Scientific Research, 1 (1), $42-55$ (2012).

14. Li, X.Z., Li, F.B., Yang, C.L. and Ge, W.K., Photocatalytic activity of $\mathrm{WO}_{\mathrm{x}}-\mathrm{TiO}_{2}$ under visible light irradiation. J. Photochem. Photobiol. A 141, 209- 217 (2001).

15. Kuen-Song Lin, Hao-Wei Cheng, Wen-Ru Chen and Chian-FuWu, Synthesis, characterization, and adsorption kinetics of titania nanotubes for basic dye. Wastewater Treatment Adsorption, 16, 47-56 (2010). 
16. Tomoko Kasuga, Formation of titanium oxide nanotubes using chemical treatments and their characteristic properties. Thin Solid Films, 496, $141-$ 145 (2006).

17. APHA, AWWA and WPCF, "Standard Methods for the Examination of Water and Wastewater", $20^{\text {th }}$ ed., APHA, AWWA,WPCF, Washington, DC (1998).

18. Tohru Sekino, Synthesis and applications of titanium oxide nanotubes, "Inorganic \& Metallic Nanotubular materials, Recent Technologies and Applications", ISBN: 978-3-642-03620-0.

19. Štengl, V., Bakardjieva, S. and Murafa, N., Preparation and photocatalytic activity of rare earth doped $\mathrm{TiO}_{2}$ nanoparticles. Materials Chemistry and Physics, 114 (1), 217-226 (2009).

20. Hahn, R., Schmidt-Stein, F., Salonen, J., Thiemann, S., Song, Y.Y., Kunze, J., Lehto, V.P. and Schmuki, P., Semimetallic $\mathrm{TiO}_{2}$ nanotubes. Angew. Chem. 121, 7372 (2009).

21. Akurati, K.K., Vital, A., Dellemann, J.P., Michalow, K., Graule, T., Ferri, D. and Baiker, A., Flamemade $\mathrm{WO}_{3} / \mathrm{TiO}_{2}$ nanoparticles: relation between surface acidity, structure and photocatalytic activity. Appl. Catal. B: Environ. 79, 53-62 (2008).

22. Asiltürk, M., Sayılkan, F. and Arpac, E., Effect of Fe3+ ion doping to $\mathrm{TiO}_{2}$ on the photocatalytic degradation of malachite green dye under UV and Vis-irradiation, J. Photochem. Photobiol. A: Chem. 203, 64-71 (2009).

23. Matos, J., Laine, J. and Herrmann, J.M., Synergy effect in the photocatalytic degradation of phenol on a suspended mixture of titania and activated Carbon. Appl. Catal. B: Environ. 18, 281-291 (1998).

24. JiaLin, Xiaolin Liu, Shu Zhu, Yongsheng Liu and Xianfeng Chen, Anatase $\mathrm{TiO}_{2}$ nanotube powder film with high crystallinity for enhanced photocatalytic performance. Nanoscale Research Letters 10, 110 (2015).

(Received 31/10/2016; accepted 25/12/2016) 


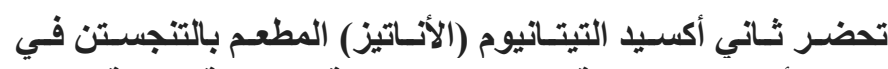

$$
\begin{aligned}
& \text { صورة أنابيب نانومترية باستخدام المعالجة الحرارية المائية } \\
& \text { حسام الدين عبد الفتاح الناظر و أميرة محمد الرافعى" }
\end{aligned}
$$

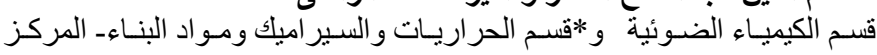

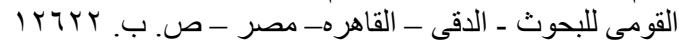

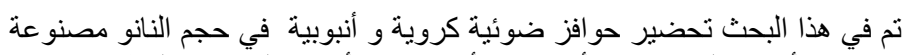

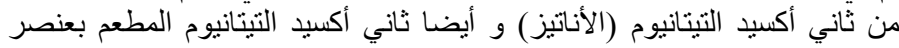

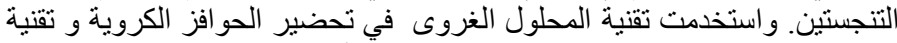

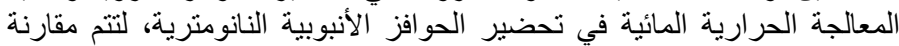

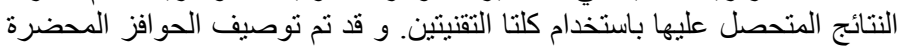

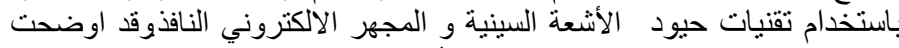

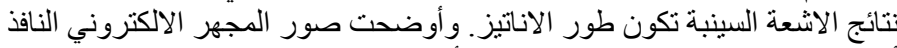

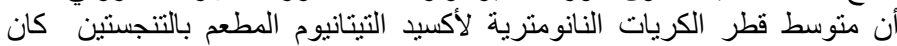

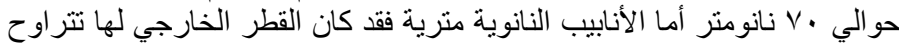

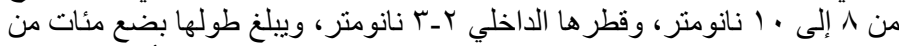

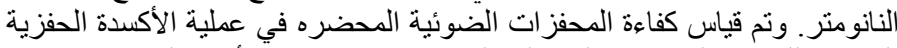

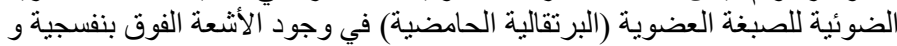

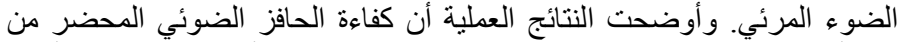

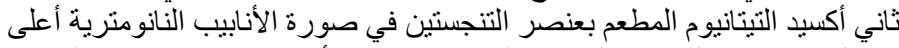

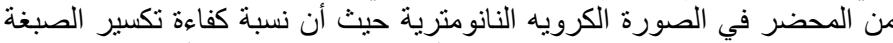

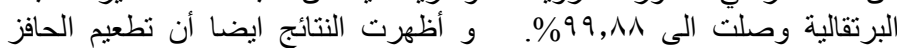
الضوئي بعنصر التنجستين قد رفع من كفاءة امتصاص الحافز الضئ للضوء المرئي. 